\title{
Could Bad Soldiers Turn Out as Good Citizens?
}

\author{
Noor Liza Adnan, Che Zuriana Muhammad Jamil, Nor Azila Mohd Noor \\ Universiti Teknologi MARA, 23000 Terengganu, Malaysia \\ noorliza@tganu.uitm.edu.my \\ Universiti Utara Malaysia, 06010 Sintok, Kedah, Malaysia \\ zuriana@uum.edu.my \\ Universiti Utara Malaysia, 06010 Sintok, Kedah, Malaysia \\ azila@uum.edu.my
}

\section{ABSTRACT}

\begin{abstract}
The issue of dysfunctional behavior (DBE) in an organization has been discussed by many. For years, those who commit DBE have always been negatively regarded and frequently perceived as bad apples affecting the whole barrel. However, recently, a new stream of research has tried to look at the possibility that employees who act in dysfunctional manner are not altogether bad. Researchers discovered that these employees might even attempt citizenship behaviors (OCB) hoping that it will assuage their guilt, restore justice, or remedy the situation. Hence this concept paper will discuss this possibility in the context of DBE occurred in performance measurement system (PMS) so as to determine if there is a relationship between these two semantically opposite behaviors. In addition, as individuals may vary in attitudes and values regarding the relationship with others, a personal construct of psychological collectivism (PCO) is proposed to moderate the DBEOCB relationship. Based on reviews of extant literature, the article first elaborates the DBE in the context of PMS before proceeding to the OCB. Propositions on the DBE-OCB relationship as moderated by PCO will be discussed based on social learning theory (SLT). Practical implications will also be discussed.
\end{abstract}

\section{Indexing terms/Keywords}

Dysfunctional behaviour, performance measurement system, organizational citizenship behaviour, psychological collectivism

\section{Academic Discipline And Sub-Disciplines}

Management accounting; business ethics; organizational behaviour;

\section{SUBJECT CLASSIFICATION}

Management Accounting Classification; Library of Congress Classification

\section{TYPE (METHOD/APPROACH)}

A concept paper based on review of extant literature

\section{Council for Innovative Research}

Peer Review Research Publishing System

\section{Journal: International Journal of Management \& Information Technology}

\author{
Vol.4, No.2 \\ editor@cirworld.com \\ www.cirworld.com, member.cirworld.com
}




\subsection{INTRODUCTION}

In management accounting, performance measurement system (hereafter, PMS) takes an important role in an organization control system that provides quantitative indicators in monitoring performance, identifying areas in need of attentions, enhancing motivation, improving communication and strengthening accountability [1]. However, PMS also has its dark side which may create dysfunction. As it is expected to facilitate the monitoring or regulating of the employees' behavior [1-4], it tends to keep 'watchful eyes' on all employees [5]. Considering that human will become skeptic when measured, there remains a motive for the managers to paint a better picture of their performance evaluation reports even if it does not represent the actual performance [5-9].

As Onsi [10] discovered, majority of managers, with full cooperation from their subordinates, were willing to manipulate information to hedge themselves against uncertainty. Argyris [7] and Flamholtz [8] had anticipated such behaviors in response to any controls and process system. They act as managers' defense mechanisms to cover up failures, or to avoid threats and embarrassment against the way the targets are set, or the way their performance is evaluated [11], especially when the target sets are unreasonable [10], or when there is a strong pressure to go beyond their assigned tasks [12-13]. However, individuals might feel guilty over their harmful behaviors. Such attribution might lead to fear of retribution which they believe may be attenuated through acts of extra-role behavior, like organizational citizenship behavior (hereafter, OCB), in the hope to assuage that guilt, restore justice, and remedy the situation [13]. Hence, whether the commission of DBE might stimulate the extra-role behaviors (OCB) among the employees is certainly worth further investigation.

Although it makes intuitive sense that individuals with a tendency to engage in one form of extra-task behavior, like OCB, will unlikely engage in dysfunctional behavior (DBE), but Spector and Fox [12] contended that this view is an oversimplification. This is proven by Sackett et al. [14] who revealed that employees who committed DBE can still be highly productive. Besides, there are also cases when the interactions between the two forms of behavior will cause one to lead to another, depending on the contextual and individual factors [13] as it may give rise to the discretionary behaviors that go above and beyond the employees' role responsibilities [15]. This indicates that the interplay between harmful and helpful behaviors is a lot more complex than the simple idea that what raises one form of behavior reduces the other [12]

However, this negative relationship might be affected by individual differences, especially the attitude or values regarding the interrelationship with others, known as psychological collectivism (PCO). Therefore, considering the effect of such personal construct may give a better comprehension of DBE-OCB relationship. Though OCB can be argued as semantically opposite form of DBE [12], but revealing how one type of deviance (which is destructive in nature) is related to another (which is constructive oriented) will contribute to a significant discovery in understanding the relationship between these behaviors in workplace [16]. Hence, further study to look into this issue would form a significant contribution [12] as intended by this paper which has the objectives of (a) to propose the possibility of the relationship between DBE and OCB; and (b) to discuss the moderating effect of PCO on the DBE-OCB relationship.

\subsection{LITERATURE REVIEW AND HYPOTHESES DEVELOPMENT}

\subsection{Dysfunctional Behaviour}

Dysfunctional behavior (hereafter, DBE) in the context of PMS actually originated from the seminal work of Argyris [5] which illustrates how budget process leads to the unintended DBE as a result of negative employees' perception associated with budget. He discovered that budgets actually affects people so directly that employees frequently perceive it as a basis for both rewarding and also penalizing. In 1956, Ridgway [17] further supported Argyris's work and proposed that this DBE actual stems from the lack of understanding of motivational and behavioral consequences of PMS that will lead to indiscriminate use, undue confidence and reliance in the system that may eventually result in side effects and reactions outweighing its benefits. The unequivocal findings of two studies by Hopwood [18] and Otley [11] have invited further probes into this area by other researchers. Birnberg, Turopolec and Young [19] then came up with a more elaborative account of DBE in accounting. These early studies have somehow motivated others to keep exploring and developing the research issue besides introducing other variables.

In the context of performance measurement and control system, Jaworski and Young [6] defined DBE as “... actions in which a subordinate (purposefully) attempts to manipulate elements of an established control system for his own purposes" (p. 18). Soobaroyen [9] then summarized that managerial DBE may constitute any behavior "but with common and underlying objectives: to use the rules and procedures to one's advantage; or with a view to avoid a potential threat to one's position/standing in the organizations" (p. 104). Jaworski and Young [6] provided a straight-forward guide in recognizing a DBE - a subordinate's behavior is dysfunctional if he knowingly violates established control system rules and procedures. This behavior has attracted a lot of attention since it may harm the organizations as it grants privileges to the managers' interest in a way that do not benefit the organization [20].

There are many forms of DBE that have been discussed in the literature. Jaworski and Young [6] came up with two captions, which are gaming and information manipulation. They defined 'gaming performance indicators' as "...chooses an action which will achieve the most favourable personal outcome regardless of the action the superior prefers" ( $\mathrm{p}$. 18). It occurs when subordinates attempt to maximize their performance on an indicator though it is not consistent with what is desired by the firm. "Information manipulation" has been redefined as "...subordinates alter the free flow of information, report only those aspects of an information set that is in their best interest, or in the extreme, falsify data and company records." (p. 19). Though there are other forms of DBE, like budgetary slack and management myopia, this paper will only 
focus on one form of DBE, information manipulation, as it is the most common and very prevalent yet are being taken for granted as it is seen as necessary for the survival of not only the members of the organization, but also the organization itself [7].

Rooted from the tension, fear of embarrassment, or just the intention to paint a desired picture of their performance, several mechanisms have been suggested in the extant literatures to trigger the DBE. Among them are the properties of PMS implemented like a highly embedded PMS [21], or an imbalanced system that emphasizes on single high priority targets [6, 22-23] or PMS employing excessive performance measures [23]. Such PMS will cause the employees to believe that the measures that they are assessed against is incomplete [22], inaccurate [24], or only consider a limited number of their required tasks, especially the wrong tasks [6]. This may cause them to lose trust in the measures and begin to rationalize that manipulating data is indeed a proper way to achieve a better performance report especially when their score is relatively low [24]. Besides, when an organization tolerates measures manipulation, Jaworski and Young [6] noted such an act of one employee will trigger the same intention among his peers for fear that his performance evaluation might suffer if he goes against them.

Besides, Flamholtz [8] opined that though rewards could be a powerful incentive to motivate and reinforce behaviour, but it can also lead to a huge amount of pressure and opportunity for managers to manipulate information in the hope of earning higher bonus [24-25]. As Schweitzer, Ordonez and Douma [26] argued, goal setting would lead employees to misrepresent their performance and overstate their productivity when they fall short of their target. Further, to avoid unwelcome attention that will invite hassle, close scrutiny or audit, employees may manipulate the measures that his team either performs very well or very badly [24]

\subsection{Organizational Citizenship Behavior (OCB)}

OCB, or the "good soldier" syndrome was introduced by Bateman and Organ in 1983 [15]. Bolino [15] cited from Organ (1988, p. 4) who defined OCB as "individual behavior that is discretionary, not directly or explicitly recognized by the formal reward system, and that in aggregate promotes the effectiveness functioning of the organization,". OCBs, then, are behaviours that are regarded as extra-role instead of in-role and must be discretionary in nature, implying that they are not an enforceable requirement of an individual's job [27]. Therefore, committing this kind of behavior is not usually rewarded, but, the failure to commit such act would also not generally invite punishment, like helping a colleague with their tasks, willingly participate in organization's activities, and tolerate temporary inconveniences without complaints.

Podsakoff et al. [28] posited that OCBs would bring many benefits to an organization, like enhancing coworkers and managerial productivity besides freeing up resources to enable more productive pursuits. Besides, OCB helps to coordinate activities both within and across work groups, resulting to the strengthened organization's ability to attract and retain the best employees. As such it will increase the stability of the organization's performance while enabling the organization to adapt more effectively to environmental changes. With such benefits it is claimed to contribute, organizations have no doubt tried to come up with various programs to instill and encourage such behaviors among their employees.

Bolino [15] summed up two motivational factors motivating OCBs. First, OCBs might stem from employees' job attitudes, where engaging in OCBs are seen as necessary in order to reciprocate the actions of their organization. Second, OCBs reflect an employee's predisposition to be helpful, cooperative or conscientious. In their review of past literatures on the antecedents of OCB, Podsakoff et al. [28] noted that OCB is mainly triggered by employees' morale, like job satisfaction, the level of organizational commitment, their perceptions of fairness and leader supportiveness, and also the strong influence of dispositional variables, like conscientiousness, agreeableness, positive affectivity, task and organizational characteristics, leadership behaviors, and role perception. In short, OCB can be seen as a reflection of a disposition or a sense of obligation of an individual's desire to help others or the organization, hence turning them into "good soldiers" or "good citizen".

\subsection{The Influence Of Dysfunctional PMS Behavior On Organizational Citizenship Behavior}

In contrast to numerous studies exploring the antecedents of DBE, there is a paucity of research examining the influence of DBE in an organization. It is unfair to classify 'information manipulation' as outright unethical as those committing such act might have strong ethical justifications. In the case of DBE in the PMS, not all dysfunctional acts can be read as unethical and some are even encouraged by the top management [29].

Admittedly, so very few papers that look into the relationship of DBE and OCB can be found from the published research database. This is not surprising, though, as this is a new area of interest that has just began to gain momentum due to the paradoxically opposite semantics of both behaviors [30], with most studies were dated back to the last ten years. These two opposite forms of extra-task behaviors, (i) DBE (behaviors that might harm the organization), and (ii) OCB (behaviors that might help the organization), have been dealt with separately until recently [12], when researchers began to conceptually and empirically integrate both behaviors in their studies [31].

Due to their opposite semantics, some researchers began to query about the possibility that these two constructs might actually be the opposite ends of the same single continuum $[14,32]$ as there is substantial content and items overlap between OCB and DBE in their currently available measures [32]. However, a few studies conducted to explore the construct validity of self-reported DBEs and OCBs did discover that they are indeed two separate unique constructs, and are negatively correlated [like $14,30,32,33$, hence eliminating the queries and fostering the integrity of the research in 
this area. Besides, Dalal et al. [30] discovered that the two behaviors are affect-driven that exhibited considerable withinperson variation, with DBE exhibiting a more dynamic nature than OCB.

Empirical studies on OCB and DBE have mostly focused not on the direct relationship between DBE and OCB, but rather on how factors like job affect or job cognition [30,34], or emotion and environmental conditions [35-36] would affect both behaviors. In short, these studies actually focused on how the same antecedents or the possibility of different antecedents can predict both behaviors. Many of the papers published also are concept papers [12-13], trying to put forth their ideas that called for further empirical investigations to advance the knowledge in this area.

Though the scarce previous researches mainly reported negative relationship of these two constructs [like 14, 30, 32, 33], but some also reported a small positive relationship [37], as well as non-significant [36]. However, there is a growing evidence that the negative DBE-OCB relationship is an oversimplification, and there might be circumstances when the two might be positively related [12]. This is in line with Dalal's [31] proposition when he discovered that there are methodological moderators that have substantial effects on the observed relationship between the two and hence questioned their strong negative interrelationship. This proposition is also supported by Spector, Bauer, and Fox [38] and Miles et al. [36].

On the basis of construct definitions, when a strong negative relationship between OCB and DBE exists, one might expect that employees who typically engage in DBE will tend not to engage in OCB. However, Sackett et al. [14] discovered that some of their respondents did emerge as simultaneously good citizens while still engage in high levels of DBE. Hence, it indicates that the same actor can perform both forms of behavior within the same environment [30, 38-39]. Furthermore, even the results of individual studies and meta-analyses revealed that the frequency of DBE and OCB within individuals is quite modestly related [12]. Hence, Spector and Fox [12] postulated that individuals do not behave exclusively in either harmful or helpful ways. Behavior has also been shown to be discrete and episodic, and hence temporally dynamic, indicating that a person would engage in very different amounts of behaviors on different occasions [40]. Dalal et al. [30] argued that even a person with a high trait level of DBE would not harm his or her organization on every possible occasion, and at times, might even resort to OCB. Yet, no study this far have examined the within-person relationship between OCB and DBE [30].

Social learning theory (hereafter, SLT) posited that employees who feel fairly treated, highly respected and not being pressured to perform beyond their capability, are not likely to engage in DBE and are willing to exert into extra-role behaviors so as to reciprocate their peers or organization. However, under the opposite circumstances, they might resort to DBE so as to maintain equilibrium between them and the organization [41]. This is made worse in a hectic working environment where work-related stress is high which promotes an environment that gives primacy to completing individual's task [42]. This is especially true in the situation where the success of an individual employee is measured by the achievement of the performance target previously set. The pressure to achieve this target would invite the attempts of information manipulation. Such DBE committed under the pressure of a hectic working environment would limit the desire of its employees to help others. Since SLT also assumes that individuals learn from their environment and imitate the behaviors of others, hence an environment that encourages DBE would reduce the proclivity towards OCB and vice versa.

Likewise, it can always be argued that managers might hold different ethical stance, which would determine whether or not they are to engage in DBE, and subsequently their effort to extend helping behavior. As such, some managers who are less ethical might manipulate information for personal gratification, like achieving target for earning reward, for promotion, or simply for earning good reputation. Such a person can be considered as less considerate of his/her subordinates. This assumption seems intuitively logic as one who has a proclivity to commit DBE is more likely to hold lower moral values, is more self-centered, and less sensitive to the consequences of his/her action. As OCB is a voluntary behavior, it can well be expected that he/she would have a lower tendency to engage in OCB, that leads to the following hypothesis:

H1: There is a negative relationship between the managers' dysfunctional behavior and their propensity to engage in organizational citizenship behavior.

\subsection{Moderating Variable: Psychological Collectivism}

As previously discussed, extant literatures, though admittedly few, exhibit mixed findings about the nature of the DBEOCB relationship. Though majority of the findings noted a modestly to strongly negative relationship, but some also discovered a positive or insignificant relationship. This inconsistency lends support to the need to examine the possibility of a moderating variable that might influence the relationship of the two constructs. Intuitively, individuals higher in DBE would have a lower tendency to perform OCB, as it is more appealing to assume that they are more self-centered, hence are more unlikely to help others by engaging in OCB. However, ignoring the fact that individuals may vary in attitudes and values regarding the relationship with their colleagues, subordinates, or superiors, may give spurious effect to this relationship. Therefore, taking into account the effect of such personal construct may give a better comprehension about the relationship of DBE-OCB.

One of these personal constructs, psychological collectivism (hereafter, PCO), is selected in this paper as it is one of the most researched cultural and personal dimensions in management [43] that explains the behavior of an individual especially in the interpersonal relationship. Its Individualism-Collectivism dichotomy (hereafter, I-C) becomes one of the most commonly used measurement to differentiate and categorize social patterns and forms of interpersonal relationship [44]. Though PCO was coined by Hofstede in 1980 as a key characteristic that differentiated national cultures, but a variety of researchers have studied PCO as an important between-culture characteristic or a within-culture individual difference with significant implications for cooperation in groups [45]. 
PCO, through its I-C dichotomy, differentiates social pattern into two categories, namely individualism and collectivism. Individualism has been defined as "an orientation towards self as an autonomous individual" while collectivism is described as "an orientation towards self as embedded in a complex web of social relationship" [46]. People who are highly individualist draw lucid separating boundaries between the self and others, hence having a tendency to direct their behavior to reflect individual opinions and values. They tend to prioritize self-interest or personal goals, achievement and freedom, and value competitiveness, and firmly appreciate their unique qualities they believe distinguish them from others [47]. However, they still encourage group cooperation if such cooperation is instrumental to achieving personal goals [46].

On the contrary, Ramamoorthy and Carroll [47] portrayed highly collectivist people as those who define themselves by their group membership and value harmonious relationships by emphasizing on sharing, duties and obligations, and maintain relationships with the group even at the expense of personal benefits. As such, the well-being of the group takes primacy over individual desires and pursuits. Hofstede (1980), as cited by Noordin and Jusoff [48], stated that collectivists closely cooperate to accomplish the organization's goals, hence creating a sense of interdependence that invites loyalty, and joint obligation to the system leading to a more co-operative and better informal communication and co-ordination among the group members. Hence, the more collectivist a person is, the better the relationship and the stronger the bond the person would develop with their group members [45]. Individualists and collectivists would respond differently to the social environment of their workgroup [49]. This indicates that the extent to which certain behaviors are related to individual outcomes may depend on the degree of I-C an individual holds [50]

\subsection{The Direct And Moderating Effects Of Psychological Collectivism}

PCO is an important cultural or personal construct that may explain the behavior of an individual, like why one resorts to OCB [like, 45, 51,52] and has been demonstrated to play a moderating role in relationships among certain constructs [like, 50, 53]. Many of these studies, like Moorman and Blakely [52], and Cohen and Avrahami [51] found a positive relationship between collectivism and OCB in such a way that collectivists are more likely to contribute to the well-being of the group even if they are not directly benefitted from such aids. Collectivists see OCBs as helpful, and being able to help the colleagues or organization is seen as necessary even if they are not required. This is in line with their collectivistic belief that helping is part of the job, not an extra-role activity [54]. Individualism is positively related to individuals with selffocused career motives, while collectivism is more closely associated with a volunteer identity [55].

Lai, Liu, and Shaffer [56] noted that in a group where its members have established a strong relationship, individualists are more likely to engage in interpersonal OCB as compared to the collectivists who are more motivated and loyal to their ingroups and organization even though the relationship among members is weak as they feel more obliged to contribute to teamwork [46]. As such, tenure does not affect the relationship of PCO-OCB among the collectivists as they would extend help to group members, irrespective of how long one has been in the group [45]. As opposed to Moorman and Blakely [52], Cohen and Avrahami [51] revealed that OCB is still prevalent in a collectivist orientation even when there is a sense of unjust mistreatment by the organization. Edrogan and Liden [50] attributed it to the nature of collectivists who put the primacy of group harmony and quality interpersonal relationship ahead of their perception of injustice. In addition, though Chung and Moon [57] discovered that collectivistic and individualistic employees are both likely to engage in interpersonal constructive behavior, but individualists exhibit higher tendency to report their coworkers' wrongdoing. Collectivists may be more likely to feel discomfort reporting other's wrongdoings as it might damage interpersonal relationships that can disrupt group harmony. However, they tend to resort to soft influence tactics, like ingratiation, when they perceived injustice or other deviant behaviors [50].

In the previous section, DBE has been hypothesized to have a negative relationship with OCB, implying that the higher the tendency a manager to commit DBE, the less likely the same manager would resort to helping behavior. Through the definition dimension, social learning theory (SLT) postulates that an individual may be embedded with cultural values that they grow up in, that would influence his/her interrelationship behavior or how they respond to others [58]. One enclosed in an individualism-oriented culture may be encouraged to prioritize personal outcome, while a collectivism-oriented culture would promote group harmony and group achievement [46]. Hence, it can be hypothesized that those high in collectivism would believe that group achievement is of paramount important and harmonious relationship among group members would take precedence over other considerations. Collectivists would strongly feel obligated to extend help to members in the organization even if such behavior is not part of their job requirement. Even if a manager shows a high tendency to commit DBE, he/she would still put primacy of achieving the group success over their own self-interest. In such a case, engaging in OCB is seen as an active way to invite positive outcomes, like better job performance or better achievement. Since self-interest is not seen as utmost important, sacrificing their time and effort to engage in OCB would not amount to a matter of concern to a collectivist manager. Hence, it is hypothesized that:

H2: The relationship between dysfunctional behaviour and organizational citizenship behaviour is moderated by psychological collectivism such that the negative relationship is weaker when collectivism is higher.

\subsection{CONCLUSION AND PRACTICAL IMPLICATIONS}

From the above discussion, it can be concluded that in an organization, an individual can, at the same time, be a bad citizen and a good soldier. Hence, the interplay of the constructive and destructive behavior is much more complex and warrants further studies to fully grasp the understanding that what raises one form of behavior may not necessarily reduce the other. Rather, it is the interaction of the environment and individual employees that leads to the repertoires of behaviors within that individual which may be both constructive as well as destructive. Hence, a more elaborated study of 
these behaviors will be helpful in advancing our understanding on how people in an organization would act and respond to the work environment.

From a practical standpoint, this paper tries to propose that though PMS has been admitted as the backbone of many successful organizations, but its design and implementation, especially the target setting phase, should not be too ambitious as it may invite many unintended consequences, like the commission of DBE. Hence, a careful and elaborated target level should be set by eliciting views from various work level. Otherwise, information or measures manipulation which will produce fabricated information will become an acceptable norm, hence no longer be regarded as dysfunctional though it may lead to sub-optimal performance.

Though DBE may have the possibility to trigger OCB, it is not the intention of this paper to promote DBE so as to increase OCB. However, it only intends to bring forward the idea that those committing DBE should not be candidly labeled as bad, but investigating the underlying motive should be made a priority, especially when they obviously engage in OCBs. It might be an indicator that there is something wrong with the system that might limit its effectiveness.

Besides, as OCB is highly encouraged in an organization due to the various benefits that it may bring, still one needs to be cautious about actions design to boost the act of OCB and at the same time to curb DBE. As the relationship of DBE-OCB might not always be negative, then encouraging one might also increase the other. Such encouragement may also be interpreted by employees as unreasonable demand which may invite more DBE. Hence, careful monitoring of workloads and ensuring that everybody in the workplace does their chores would be helpful.

\section{REFERENCES}

[1] Waggoner, D.B., A.D. Neely, and M.P. Kennerly, The forces that shape organizational performance measurement systems: An interdisciplinary review. International Journal of Production Economics, 1999. 60-61: p. 53-60.

[2] Nanni, A.J., J.R. Dixon, and T.E. Vollman, Strategic control and performance measurement. Journal of Cost Management, 1990. Summer: p. 33-42.

[3] Martinez, V., What is the value of using PMS? Perspectives on Performance, 2005. 4(2): p. 16-18.

[4] Otley, D.T., Performance management: A framework for management control systems research. Management Accounting Research, 1999. 10( 4): p. 363-382.

[5] Argyris, C., Human problems with budgets. Harvard Business Review, 1953. 31(1): p. 97-110.

[6] Jaworski, B.J. and S.M. Young, Dysfunctional behaviour and management control: An empirical study of marketing managers. Accounting, Organizations and Society, 1992. 17(1): p. 17-35.

[7] Argyris, C., The dilemma of implementing controls: The case of managerial accounting. Accounting, Organizations and Society, 1990. 15: p. 503-511.

[8] Flamholtz, E., Effective organizational control: A framework, applications, and implications. European Management Journal, 1996. 14: p. 596-611.

[9] Soobaroyen, T., Management control systems and manager dysfunctional behaviour: An empirical study of direct, intervening and moderating effects. . 2007, The University of Wales: Aberystwyth, UK.

[10] Onsi, M., Factor analysis of behavioural variables affecting budgetary slack. The Accounting Review, 1973. July: $p$. 535-548.

[11] Otley, D.T., Budget use and managerial performance. Journal of Accounting Research, 1978. 16: p. $122-149$.

[12] Spector, P.E. and S. Fox, Counterproductive work behaviour and organizational citizenship behaviour: Are they opposite forms of active behaviour? Journal of Applied Psychology, 2010. 59(1): p. 21-39.

[13] Spector, P.E. and S. Fox, Theorizing about deviant citizen: An attributional explanation of the interplay of organizational citizenship and counterproductive work behaviour. Human Resource Management Review, 2010. 20: p. 132-143.

[14] Sackett, P.R., et al., Citizenship and counterproductive behavior: Clarifying relations between the two domains. Human Performance, 2006. 19(4): p. 441-464.

[15] Bolino, M.C., Citizenship and impression management: Good soldiers or good actors? Academy of Management Review, 1999. 24(1): p. 82-98.

[16] Warren, D.E., Constructive and destructive deviance in organizations. Academy of Management Review, 2003. 28(4): p. 622-632.

[17] Ridgway, V.F., Dysfunctional consequences of performance measurement. Administrative Science Quarterly, 1956. 1(2): p. 240-247.

[18] Hopwood, A.G., An empirical study of the role of accounting data in performance evaluation. Journal of Accounting Research, 1972. 10: p. S156-S182.

[19] Birnberg, J.G., L. Turopolec, and S.M. Young, The organizational context of accounting. Accounting, Organizations and Society, 1983. 8: p. 111-129.

[20] Simons, R., Control in an age of empowerment. Harvard Business Review, 1995. 67(2): p. 80-88.

[21] Lau, C.M., The effect of emphasis on tight budget targets and cost control on production and marketing managers' propensity to create slack. British Accounting Review, 1999. 31: p. 415-437.

[22] Hirst, M.K., Accounting information and the evaluation of subordinate performance: A situational approach. The Accounting Review, 1981. LVI(4): p. 771-784.

[23] Keasey, K., P. Moon, and D. Duxbury, Performance measurement and the use of league tables: some experimental evidence of dysfunctional consequences. Accounting and Business Research, 2000. 30(4): p. 275-286.

[24] Fisher, C. and B. Downes, Performance measurement and metric manipulation in the public sector. Business Ethics: A European Review, 2008. 17 (3): p. 245-258. 
[25] Tang, T.L.-P., Y.-J. Chen, and T. Sutarso, Bad apples in bad (business) barrels - The love of money, machiavellianism, risk tolerence and unethical behaviour. Management Decision, 2008. 46(2): p. $243-263$.

[26] Schweitzer, M.E., L. Ordonez, and B. Douma, Goal setting as a motivator of unethical behaviour. Academy of Management Journal, 2004. 47(3): p. 422-432.

[27] Organ, D.W., Organizational citizenships behavior: It's construct cleanup time. Human Performance, 1997. 10: p. 8597.

[28] Podsakoff, P.M., et al., Organizational citizenship behaviors: A critical review of the theoretical and empirical literature and suggestions for future research. Journal of Management, 2000. 26(3): p. 513-563.

[29] Merchant, K.A. and J.-F. Manzoni, The achievability of budget targets in profit centers: A field study. The Accounting Review, 1989. LXIV( 3): p. 539-558.

[30] Dalal, R.S., et al., A within-person approach to work behaviour and performance: Concurrent and lagged citizenshipcounterproductivity associations, and dynamic relationships with affect and overall job performance Academy of Management Journal, 2009. 52(5): p. 1051-1066.

[31] Dalal, R.S., A meta-analysis of the relationship between organizational citizenship behavior and counterproductive work behavior. Journal of Applied Psychology 2005. 90(6): p. 1241-1255.

[32] Kelloway, E.K., et al., Self-reported counterproductive behaviors and organizational citizenship behaviors: Separate but related constructs. International Journal of Selection and Assessment, 2002. 10(1/2): p. 143-151.

[33] O'Brien, K.E. and T.D. Allen, The relative importance of correlates of organizational ctizenship behavior and counterproductive work behavior using multiple sources of data. Human Performance, 2008. 21: p. 62-88.

[34] Lee, K. and N.J. Allen, Organizational citizenship behavior and workplace deviance: The role of affect and cognitions. Journal of Applied Psychology 2002. 87(1): p. 131-142.

[35] Spector, P.E. and S. Fox, An emotion-centered model of voluntary work behavior: Some parallels between counterproductive work behavior and organizational citizenship behavior. Human Resource Management Review 2002. 12: p. 269-292.

[36] Miles, D.E., et al., Building an integrative model of extra role work behaviors: A comparison of counterproductive work behavior with organizational citizenship behavior. International Journal of Selection and Assessment 2002. 10(1/2): p. 51-57.

[37] Fox, S., et al. (2011) The deviant citizen: Measuring potential positive relations between counterproductive work behaviour and organizational citizenship behaviour. Journal of Occupational and Organizational Psychology May, 122 DOI: DOI: 10.1111/j.2044-8325.2011.02032.x.

[38] Spector, P.E., J. Bauer, and S. Fox, How do counterproductive work behaviour and organizational citizenship behaviour interrelate?, in Society for Industrial and Organizational Psychology. 2009.

[39] Fox, S., et al., Does your coworker know what you're doing? Convergence of self-and peer-reports of counterproductive work behavior. International Journal of Stress Management, 2007. 14(1): p. 41-60.

[40] Beal, D.J., et al., An episodic process model of affective influences on performance. Journal of Applied Psychology, 2005. 90: p. 1054-1068.

[41] Ames, O.K. (2011) Cognitive influences on ethical decision-making in organizations. DRI: The Voice of Defense Bar.

[42] Ayupp, K. and T.M. Nguok, A study of workplace stress and its relationship with job satisfaction among officers in the Malaysian banking sector. Interdisciplinary Journal of Contemporary Research in Business, 2011. 2(11): p. $403-417$.

[43] Earley, P.C. and C.B. Gibson, Taking stock in our progress on individualism-collectivism: 100 years of solidarity and community. Journal of Management, 1998. 24(3): p. 265-304.

[44] Venkatraman, S. and G. Reddy, Gender differences and similarities on the cultural dimension of individualism and collectivism: A study on public sector bank employees. Indian Journal of Education and Information Management, 2012. 1(2): p. 55-63.

[45] Van Dyne, L., et al., Collectivism, propensity to trust and self-esteem as predictors of organizational citizenship in a non-work setting. Journal of Organizational Behavior, 2000. 21: p. 3-23.

[46] Ramamoorthy, N. and P.C. Flood, Employee attitudes and behavioural intentions: $A$ test of the main and moderating effects of individualism-collectivism orientations. Human Relations, 2002. 55(9): p. 1071-1096.

[47] Ramamoorthy, N. and S.J. Carroll, Individualism/collectivism orientations and reactions toward alternative human resource management practices. Human Relations, 1998. 51(5): p. 571-588.

[48] Noordin, F. and K. Jusoff, Individualism-collectivism and job satisfaction between Malaysia and Australia. International Journal of Educational Management, 2010. 24(2): p. 159-174.

[49] Hui, C.H. and C. Yee, The shortened individualism-collectivism scale: Its relationship to demographic and wrokrelated variables. Journal of Research in Personality, 1994. 28: p. 409-424.

[50] Erdogan, B. and R.C. Liden, Collectivism as a moderator of responses to organizational justice: Implications for leader-member exchange and ingratiation. Journal of Organizational Behavior, 2006. 27: p. 1-17.

[51] Cohen, A. and A. Avrahami, The relationship between individualism, collectivism, the perception of justice, demographic characteristics and organizational citizenship behaviour. The Service Industries Journal, 2006. 26(8): p. 889-901.

[52] Moorman, R.H. and G.L. Blakely, Individualism-collectivism as an individual difference predictor of organizational citizenship behaviour. Journal of Organizational Behavior, 1995. 16: p. 127-142.

[53] Hui, C.H., K. Cheng, and Y. Gan, Psychological collectivism as a moderator of the impact of supervisor-subordinate personality similarity on employees' service quality. Applied Psychology: An International Review, 2003. 52(2): p. 175-192.

[54] de León, M.C.D. and M.A. Finkelstein, Individualism/collectivism and organizational citizenship behavior. Psicothema, 2011. 23(3): p. 401-406. 
[55] Finkelstein, M.A., Individualism/collectivism: Implications for the volunteer process. Social Behavior and Personality, 2010. 38(4): p. 445-452.

[56] Lai, C.T.C., X. Liu, and M.A. Shaffer, Interpersonal citizenship behaviors of employees in Greater China: A social capital perspective, in Academy of International Business. 2004: Stockholm, Sweden.

[57] Chung, Y.W. and H.K. Moon, The moderating effects of collectivistic orientation on psychological ownership and constructive deviant behavior. International Journal of Business and Management, 2011. 6(12): p. 65-77.

[58] Bandura, A., Social Learning Theory. 1977, Englewood Cliffs, NJ: Prentice-Hall.

\section{Author' biography with Photo}

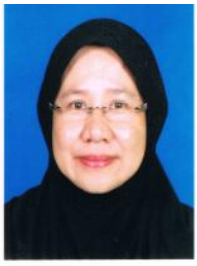

Noor Liza Adnan has bee a senior lecturer in Management Accounting at Faculty of Accountancy, Universiti Teknologi MARA, Malaysia for more than 10 years. She is currently pursuing he PhD at Universiti Utara Malaysia, Kedah, Malaysia in the area of Manahement Accounting, specifically, performance measurement system. Her research interests are related to management control system, performance measurement system and problem-based learning in higher educations. She has experienced teaching management accounting and strategic management. She has published several articles in the local and international refereed journals.

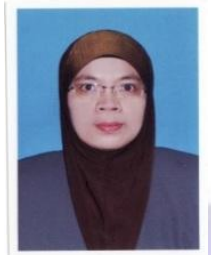

Che Zuriana Muhammad Jamil is a senior lecturer in Management Accounting at College of Business, University of Utara Malaysia since 10 years ago. She obtained her PhD degree from Bangor University, Wales, United Kingdom in 2008. Her research interests are related to environmental management control system, performance measurement system and environmental management practice in all types of industries. She has experienced teaching and conducting research in management control system and environmental management course. She has published several articles in the local and international refereed journals.

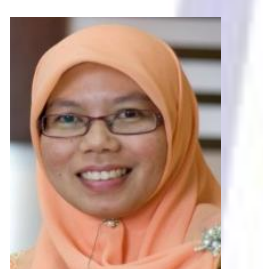

Nor Azila Mohd Noor is an Associate Professor in Marketing and the Head of the Consumer and Market Analysis Competency Centre at the Othman Yeop Abdullah Graduate School of Business, University Utara Malaysia (UUM), Malaysia. She received her MSc. (Marketing) in 1996 and Ph.D in 2004. She has published articles in professional journals such as Journal of Quality Assurance in Hospitality and Tourism, World Applied Sciences Journal, International Journal of Retailing and Distribution, Journal of Internet Banking and Commerce, International Journal of Business \& Society and International Retail and Marketing Review. Her research interests include relationship marketing, customer relationship management, green marketing, consumer behaviour and retailing. 